\title{
Violência obstétrica institucional: uma questão sobre os direitos da mulher
}

\author{
Institutional obstetric violence: a question about women's rights \\ Violencia obstétrica institucional: una pregunta sobre los derechos de las mujeres
}

Recebido: 2410/2021 | Revisado: 27/10/2021 | Aceito: 28/10/2021 | Publicado: 31/10/2021

\author{
Amanda Faber Pedro Moura \\ ORCID: https://orcid.org/0000-0001-6354-0600 \\ Instituto Tocantinense Presidente Antônio Carlos Palmas, Brasil \\ E-mail: amanda_fpm@hotmail.com \\ Yasmin Ferrari Tomasoni \\ ORCID: https://orcid.org/0000-0001-5884-6488 \\ Instituto Tocantinense Presidente Antônio Carlos Palmas, Brasil \\ E-mail: yasmintomasoni@hotmail.com \\ Bianca Macêdo Guimarães \\ ORCID: https://orcid.org/0000-0002-3911-2435 \\ Instituto Tocantinense Presidente Antônio Carlos Palmas, Brasil \\ E-mail: marbijeans@gmail.com \\ Marília Ferreira Camargo \\ ORCID: https://orcid.org/0000-0003-3173-1896 \\ Instituto Tocantinense Presidente Antônio Carlos Palmas, Brasil \\ E-mail: mariliacamargo00@gmail.com \\ Mariana Do Prado Borges \\ ORCID: https://orcid.org/0000-0002-7032-8920 \\ Instituto Tocantinense Presidente Antônio Carlos Palmas, Brasil \\ E-mail: marianapb_96@ hotmail.com \\ Jandrei Rogério Markus \\ ORCID: https://orcid.org/0000-0003-1535-5042 \\ Instituto Tocantinense Presidente Antônio Carlos Palmas, Brasil \\ E-mail: jandreimarkus@gmail.com
}

\begin{abstract}
Resumo
Objetivo: Esta revisão integrativa tem como objetivo compreender através da literatura como se estabeleceu o processo institucional da violência obstétrica na mulher levando em conta que este fenômeno é reconhecido através de diferentes tipos de agressões que podem ocorrer no contexto da gestação, parto, puerpério, como também em situações de aborto, pós-aborto e ciclo reprodutivo. Metodologia: Trata-se de uma revisão integrativa de literatura onde foram selecionados artigos utilizando as plataformas do SciELO, PUBMED e MEDLINE e foram escolhidos para o espaço amostral da pesquisa apenas artigos publicados em português, inglês ou espanhol e uma cartilha, que retrataram a temática referente à ocorrência da violência obstétrica e artigos publicados e indexados nos referidos bancos de dados dos últimos 21 anos. Nesta revisão integrativa, realizamos atividades de busca de informações, compilação e registro dos artigos selecionados. Resultados e discussão: A violência obstétrica ainda é uma realidade, ocorrendo principalmente com mulheres de baixa renda e escolaridade, expressando-se através de abusos verbais, procedimentos desnecessários, entre outras formas. Isso se dá pela falta de preparo da equipe de saúde, leis e a não conscientização da mulher. Conclusão: A Violência obstétrica caracteriza-se por práticas inadequadas contra a mulher no período gestacional. É notório o prejuízo psicológico a esta parturiente. Para diminuir essa realidade são necessários projetos de leis que amparam as mulheres, a conscientização das mesmas durante o pré-natal, e uma formação mais humanizada dos futuros profissionais da saúde.
\end{abstract}

Palavras-chave: Violência obstétrica; Direitos da mulher; Obstetrícia.

\begin{abstract}
Objective: This integrative review aims to understand through the literature how the institutional process of obstetric violence in women was established, taking into account that this phenomenon is recognized through different types of aggression that can occur in the context of pregnancy, childbirth, puerperium, such as also in situations of abortion, post-abortion and reproductive cycle. Methodology: This is an integrative literature review where articles were selected using the platforms of SciELO, PUBMED and MEDLINE and only articles published in Portuguese, English or Spanish and a primer, were chosen for the sample space of the research, which portrayed the theme related to the occurrence of obstetric violence and articles published and indexed in these databases in the last 21 years. In this integrative review, we carried out activities to search for information, compile and register the selected articles. Results and discussion: Obstetric violence is still a reality, occurring mainly with low-income and low-educated women, expressing itself through verbal abuse, unnecessary procedures, among other ways. This is due to the lack of
\end{abstract}


preparation of the health team, laws and women's lack of awareness. Conclusion: Obstetric violence is characterized by inappropriate practices against women during pregnancy. The psychological damage to this parturient is notorious. To reduce this reality, bills that support women, their awareness during prenatal care, and a more humanized training of future health professionals are needed.

Keywords: Obstetric violence; Women's rights; Obstetrics.

\section{Resumen}

Objetivo: Esta revisión integradora tiene como objetivo comprender a través de la literatura cómo se estableció el proceso institucional de violencia obstétrica en la mujer, tomando en cuenta que este fenómeno se reconoce a través de diferentes tipos de agresiones que pueden ocurrir en el contexto del embarazo, parto, puerperio, tales como también en situaciones de aborto, postaborto y ciclo reproductivo. Metodología: Se trata de una revisión de literatura integradora donde se seleccionaron artículos utilizando las plataformas de SciELO, PUBMED y MEDLINE y solo se eligieron artículos publicados en portugués, inglés o español y una cartilla, para el espacio muestral de la investigación, los cuales retrataron la temática relacionada con la ocurrencia de violencia obstétrica y artículos publicados e indexados en estas bases de datos en los últimos 21 años. En esta revisión integradora, realizamos actividades de búsqueda de información, recopilación y registro de los artículos seleccionados. Resultados y discusión: La violencia obstétrica sigue siendo una realidad, ocurriendo principalmente con mujeres de bajos ingresos y bajo nivel educativo, expresándose a través del abuso verbal, procedimientos innecesarios, entre otras formas. Esto se debe a la falta de preparación del equipo de salud, las leyes y el desconocimiento de las mujeres. Conclusión: La violencia obstétrica se caracteriza por prácticas inapropiadas contra la mujer durante el embarazo. El daño psicológico de esta parturienta es notorio. Para reducir esta realidad, se necesitan proyectos de ley que apoyen a las mujeres, la sensibilización durante la atención prenatal y una formación más humanizada de los futuros profesionales de la salud.

Palabras clave: Violencia obstétrica; Derechos de la mujer; Obstetricia.

\section{Introdução}

Para que se compreenda de forma clara o que é a violência obstétrica, inicialmente contextualiza-se essa ocorrência em diferentes cenários de cuidado com a mulher. A violência obstétrica pareceu ser um termo um tanto quanto assustador quando dirigimos o pensamento a uma possível tortura física durante o trabalho de parto, mas foi necessário compreender que esse termo é muito mais abrangente pois engloba ações psicológicas e físicas, como por exemplo a forma como a equipe médica conversou com a mulher utilizando de termos pejorativos, até o uso de manobras extremamente traumáticas e desnecessárias (Rodrigues et al., 2018).

Outrossim, a compreensão do fenômeno da Violência Obstétrica foi baseada no conceito estereotipado de gênero socialmente difundido, em que as mulheres, vistas como o sexo frágil, precisaram ser mantidas sob a autoridade patriarcal, nesse cenário, incluiu-se os profissionais, que decidiram pela paciente, privando-a dos seus direitos de escolha, transformando o parto em um ato profissional sujeito a práticas violentas (Barboza \& Mota, 2016).

No Brasil, muitos profissionais da saúde preferiram se omitir para essa situação do que atuar contra uma hierarquia enraizada e idealizada, tanto pela equipe médica quanto pela população. Consequentemente, muitos membros da equipe ficaram com medo de se indispor com os médicos ou até mesmo com a justiça ao denunciarem algum tipo de abuso sob a ameaça de perder seu emprego. Logo, isso aconteceu pelo fato de não existir nenhuma lei federal que amparava as mulheres nesses casos de violência obstétrica (Andrade \& Aggio, 2014).

Em contrapartida, em novembro de 2006 foi aprovada na Venezuela a Lei Orgânica dos Direitos da Mulher a uma Vida Livre de Violência tornando-se assim o primeiro país a promulgar uma lei que caracterizava a violência obstétrica como a apropriação do corpo feminino e reprodutivos pelos profissionais de saúde. Isso foi levantado devido a um tratamento desumano por parte dos profissionais, ao uso abusivo de medicações e intervenções desnecessárias nos processos fisiológicos da mulher grávida, evidenciando uma perda de autonomia e liberdade de escolha, afetando negativamente a qualidade de vida das mulheres (Rodrigues et al., 2018).

Diante disso, tornou-se necessário entender como ocorre a violência obstétrica, mas em virtude da falta de uma lei que determinava o que se configura este episódio essa se torna uma tarefa difícil. Fez-se necessário, portanto, a disseminação de 
informações a respeito do tema em âmbito acadêmico, institucional e populacional para que houvesse a criação de um projeto de lei efetivo que visasse amparar os direitos da mulher (Jardim \& Moderna., 2018).

Esta revisão integrativa tem como objetivo compreender através da literatura como se estabeleceu o processo institucional da violência obstétrica na mulher levando em conta que este fenômeno é reconhecido através de diferentes tipos de agressões que podem ocorrer no contexto da gestação, parto, puerpério, bem como em situações que englobam assistência a casos que envolvam aborto, pós-aborto e ciclo reprodutivo.

\section{Metodologia}

Foi utilizado o método de pesquisa bibliográfica, por meio de uma revisão integrativa de literatura, que se trata da síntese de conhecimentos e reunião dos resultados de estudos relevantes que permite fundamentar a prática sobre determinado tema em conhecimentos científicos (Botelho, Cunha \& Macedo, 2011; Sousa, 2017).

A seleção dos artigos para composição do espaço amostral se deu por meio de consulta de bases de dados eletrônicos Scientific ElectronicLibrary Online (SciELO), National Library of Medicine (PUBMED) e Medical Literature Analysis and Retrievel System Online (Medline). O trabalho foi realizado nos meses novembro de 2020 à agosto de 2021.

$\mathrm{O}$ estudo pautou-se na seguinte questão de pesquisa: Como se configura a violência obstétrica institucional? O que pode ser feito a respeito?

Foram utilizados para a busca dos artigos, os seguintes descritores e suas combinações nas línguas portuguesa, inglesa e espanhola: violência obstétrica, parto e obstetrícia. Os critérios de inclusão das referências foram definidos a inclusão apenas de artigos publicados em português, inglês ou espanhol, que retrataram a temática referente à ocorrência da violência obstétrica e artigos publicados e indexados nos referidos bancos de dados dos últimos 10 anos. Foram excluídos os artigos pagos, não associados ao tema, artigos que não foram encontrados na íntegra e as duplicações de artigos.

Dessa maneira, foram abordadas fases para chegar à revisão integrativa como, identificar o problema, fazer uma busca na literatura mediante artigos, palavras-chave, bases de dados, critérios de inclusão e exclusão, avaliação de dados, análise de dados e, uma apresentação dos dados finais, observando como estes estão relacionados e relacionados na teoria. Ao final foram selecionados 21 artigos e excluídos 5.

\section{Resultados e Discussão}

O termo Violência Obstétrica foi definido de acordo com a OMS (Organização Mundial da Saúde), como uso intencional de força física ou poder, em ameaça ou na prática que resulte ou possa resultar em sofrimento, morte, dano psicológico, desenvolvimento prejudicado ou privação dos direitos da mulher. Também se classifica a violência obstétrica em sete categorias relacionadas com abuso físico; cuidado não consentido; abuso verbal; discriminação; abandono, negligência ou recusa de assistência; detenção nos serviços (anulação da liberdade e autonomia) e imposição de intervenções obstétricas não consentidas sem bases científicas. Vale ressaltar que a violência pode ser caracterizada como uma visão patológica em relação ao parto, visto que se trata de algo fisiológico, dessa forma inibe a autonomia da mulher em relação às decisões tomadas (Andrade \& Aggio, 2014).

Estudos realizados por Diniz (2014), mostram que a violência obstétrica é diretamente proporcional ao nível de vulnerabilidade e classe econômica da mulher mais baixa, sendo estas mais propensas a sofrer esse tipo de abuso. Também enfatizaram que há uma negligência na conduta de atendimentos de mulheres que estão se expressando com choros, gritos, e nos casos de abortos provocados. Através de relatos apresentados, a grande maioria das mulheres expuseram que se sentiram ofendidas, desrespeitada e desvalorizadas por serem tratadas a base de xingamentos, gritos, ofensas, brutalidade e principalmente traumatizadas com o parto vaginal, mas que apesar disso tudo permaneceram caladas (Andrade \& Aggio, 
2014). Logo, vemos que esse problema ainda se trata de uma violência silenciosa que causa consequências físicas e psicológicas, sem que a justiça respalde suas vítimas.

O período de puerpério é um processo fisiológico natural, que pode ocorrer sem intervenções e/ou procedimentos desnecessários, levando a mulher a uma necessidade maior de apoio emocional. Procedimentos como a episiotomia, o uso de hormônios sintéticos de forma rotineira e sem critérios e o despreparo institucional e da equipe médica, com a falta de conforto e salas cirúrgicas adequadas. Esses fatores acabam tornando o que deveria ser uma das melhores experiências na vida dessas mulheres em uma das mais traumáticas por terem sua dignidade, autonomia, integridade física e mental abaladas (Silva \& Marcelino, 2014).

Uma das bases da violência obstétrica está relacionada com a bíblia, quando associaram o parto com a dor, que fez com que o parto deixasse de ser uma experiência única e prazerosa e passou a ser visto como uma consequência ou mesmo um castigo. Portanto, o pensamento de que a dor é inerente ao parto, foi sendo disseminado desde então, sendo enraizado na sociedade e nos profissionais da saúde. Quando na verdade é necessário que a mulher seja o centro, que tenha um atendimento singular respaldado na humanização, para que a qualidade seja priorizada (Andrade \& Aggio, 2014).

Ressaltam que apesar da feminização da equipe obstétrica, não fez com que ela se tornasse mais humana e segura, pelo contrário, mostrou que são as próprias mulheres responsáveis pela maioria das práticas abusivas (Rodrigues et al., 2018). Além disso, o despreparo, a imperícia, e a negligência de alguns profissionais contribuíram para a perpetuação da violência. Outrossim evidenciaram que a violência muitas vezes é pautada na hierarquia do médico sobre a mulher, como se apenas o médico tivesse acesso ao conhecimento, e isso retirou o protagonismo dela, tornando-a apenas uma coadjuvante (Andrade \& Aggio, 2014).

Nesse sentido, o Ministério da Saúde, desenvolveu o Programa Maternidade Segura, que tem como finalidade aumentar o respeito e a qualidade da atenção à mulher no momento do parto, garantindo não só informações sobre os direitos que elas têm, como também a estrutura e a equipe necessária para a assistência ao parto de forma integral e humanizada (Brasil,2000). A Coleção "Cartilha do Projeto Gênero, Violência e Direitos Humanos" realizada pelo Centro de Direitos Humanos $(\mathrm{CDH})$, propôs sete passos para garantir às mulheres práticas obstétricas mais humanizadas, garantindo a promoção da saúde desde a primeira consulta pré-natal. $\mathrm{O}$ objetivo geral da cartilha foi assegurar às mulheres os direitos referentes ao momento do parto com ela essas mulheres recebem informações e orientações nos âmbitos emocionais, físicos e econômicos (Perruso et al., 2005).

O tema ainda trouxe para a reflexão o poder e autoridade exercidos pelos profissionais da saúde em relação aos seus pacientes. Foi observado a existência de uma relação hierárquica onde o médico foi visto como autoridade e estava fixado no topo dessa hierarquia, essa suposta superioridade muitas vezes se transformava em violência e a paciente se tornava objeto de ação para que ela ocorresse. Essa dominação e opressão exercida por alguns profissionais da saúde tornou-se o pivô para que as pacientes tenham sua autonomia impedida ou anulada (Barbosa \& Mota, 2016).

Nesse sentido, a violência institucional, tal como a definimos, é reconhecida e admitida como prática comum por quase todos os entrevistados, ainda que a definição e nomeação do que seria violência institucional na visão destes profissionais tenha limites pouco claros. O termo "violência" é mais comumente associado à violência física na população em geral; e na área da saúde, a violência contra a mulher é frequentemente referida apenas à violência sexual e doméstica (Aguiar et al., 2013).

A episiotomia foi um dos procedimentos mais utilizados na obstetrícia, perdendo apenas para o corte e pinçamento do cordão umbilical. Conforme estudos, a episiotomia quando estabelecida como conduta tinha o intuito de evitar traumas perineais severos, danos no assoalho pélvico, prolapso e incontinência urinária. Apesar de terem sido classificados como uma 
conduta de prevenção, hoje se sabe que o tônus da musculatura vaginal depende mais de exercício, da sua contração e relaxamento, do que cirurgias (Palharini, 2017).

$\mathrm{Na}$ prática, a episiotomia trata-se de uma incisão cirúrgica na região da vulva, que tinha por objetivo favorecer a liberação do concepto e evitar lesões. Mas atualmente sabe-se que o procedimento quando praticado sem o consentimento da mulher, ou sem indicação configura-se como desrespeito à autonomia e integridade física e mental da mulher, tornando-se um ato de violência obstétrica no momento do parto. Essa incisão realizada na região do períneo (área muscular localizada entre a vagina e o ânus), deveria ser realizada apenas quando há perigo ou sofrimento fetal, posição de difícil acesso para o feto sair ou até mesmo pelo seu tamanho. Desse modo a prática feita rotineiramente por muitos profissionais representou na maioria das vezes um procedimento desnecessário e invasivo para a mulher (Zaami et al., 2019).

O Brasil adota um modelo majoritariamente intervencionista quando se trata de procedimentos durante o parto vaginal e estudos demonstram que tais procedimentos levam a altos índices relacionados a consequências para o neonato e até mesmo a mortalidade. Sabe-se que o parto natural, por ser o fisiológico, é o mais indicado na troca da vida intrauterina para extrauterina do recém-nascido, quanto mais natural melhor tanto para a vida da parturiente quanto do concepto. No entanto, ainda se encontram altos índices de partos cesarianos, em 2015 dos 3 milhões de partos realizados no país 55\% foram cesarianas e 45,5 partos naturais. Diante disso observa-se ainda que desses 45,5\% dos partos vaginais quase que em sua maioria são utilizadas manobras de intervenção e exemplo da episiotomia, uso indiscriminado da ocitocina, fórceps e a própria manobra de Kristeller, técnicas que a propósito não tem comprovação científica alguma acerca de sua real eficiência, por isso a importância de discorrer mais sobre o assunto. E no que diz respeito à saúde privada a proporção entre cesariana e parto vaginal ainda é maior sendo, 89,9\% de partos cesarianos (Leal et al., 2014).

Há estudos que mostram que a maioria das mulheres tem conhecimentos insuficientes em relação a violência obstétrica, o que dificulta na identificação dessas ações, consequentemente perpetuando sua prevalência (Vieira et al., 2020). Conjuntamente é visto que a formação dos novos profissionais também influencia na predominância ou não de tais atos, dado que, a banalização da violência obstétrica muitas vezes está arraigada nos profissionais responsáveis pela formação da futura equipe de saúde (Diniz et al., 2015). Logo faz se necessário a disseminação do conhecimento quanto a identificação das várias formas de violência obstétrica e uma conscientização por parte dos acadêmicos de medicina, enfermagem e equipe de saúde.

A Tabela 1 representa a seleção dos artigos analisados para realização deste estudo que consiste em uma revisão integrativa de literatura, englobando artigos originais que remetem a discussão acerca da prática da violência obstétrica institucionalizada. 
Tabela 1: Artigos selecionados para revisão integrativa de literatura.

\begin{tabular}{|c|c|c|c|}
\hline Número & Título & Ano & Resultados de estudos \\
\hline $\begin{array}{l}\text { Andrade B. P., } \\
\text { Padilha, B. Aggio, } \\
\text { C.M. }\end{array}$ & Violência obstétrica: a dor que cala & 2014 & $\begin{array}{l}\text { O estudo mostra que a violência obstétrica ainda não é vista como um ato violento } \\
\text { para muitos durante a gestação, parto e pós-parto. Além disso ela engloba práticas de } \\
\text { medicalizações do parto e o aumento de cesariana que impedem que a mulher seja a } \\
\text { protagonista em um dos momentos mais marcantes da vida. }\end{array}$ \\
\hline $\begin{array}{c}\text { Barbosa, L. P., Mota, } \\
\text { A. }\end{array}$ & $\begin{array}{l}\text { Violência obstétrica vivencias de } \\
\text { sofrimentos entre gestantes do } \\
\text { Brasil }\end{array}$ & 2016 & $\begin{array}{l}\text { A violência obstétrica é responsável pelo abalo e adoecimento físico e mental das } \\
\text { mulheres. É necessário entender que a mulher está em um momento vulnerável, e que } \\
\text { necessita de acolhimento. Também relata que as mulheres são desrespeitadas, não } \\
\text { participam do próprio parto, assim o parto deixa de ser visto como um evento natural } \\
\text { e fisiológico e passa a ser uma linha de produção. }\end{array}$ \\
\hline $\begin{array}{l}\text { Carvalho, I. Da S., De } \\
\text { Brito, R. S. }\end{array}$ & $\begin{array}{l}\text { Forma de violência obstétrica } \\
\text { vivenciadas por puérperas que } \\
\text { tiveram parto normal }\end{array}$ & 2017 & $\begin{array}{l}\text { Por muito tempo a violência obstétrica era invisível, mas atualmente é notório a sua } \\
\text { existência. Seu impacto vai muito além de atos momentâneos, pois deixa marcas } \\
\text { eternas nessas mulheres. }\end{array}$ \\
\hline $\begin{array}{l}\text { Diniz, S. G., Salgado, } \\
\text { H. D. O., Aguiar A., } \\
\text { Halana, D., F. }\end{array}$ & $\begin{array}{l}\text { Violência obstétrica como questão } \\
\text { para saúde pública no brasil: } \\
\text { origens, definições, tipologia, } \\
\text { impactos sobre a saúde materna, e } \\
\text { propostas para sua prevenção }\end{array}$ & 2015 & $\begin{array}{c}\text { A violência obstétrica é vista como um problema de saúde pública, e existem } \\
\text { diferentes causalidades, desde da formação dos profissionais até a organização dos } \\
\text { serviços de saúde. Na tentativa de diminuir essa realidade é necessário oferecer } \\
\text { informações sobre assistência ao parto desde do pré-natal, orientar sobre seus direitos } \\
\text { e informações gerais, investir na equipe de obstetrícia, divulgar a central de } \\
\text { atendimento à mulher, e dar mais visibilidade ao problema e responsabilizar seus } \\
\text { autores. }\end{array}$ \\
\hline Humanos CdD & $\begin{array}{c}\text { Coleção "Cartilhas sobre direitos } \\
\text { humanos" }\end{array}$ & 2005 & $\begin{array}{c}\text { o Ministério da Saúde desenvolveu o Programa Maternidade Segura que busca } \\
\text { conscientizar e orientar as puérperas quanto os seus direitos, e a cartilha propôs sete } \\
\text { passos que tem como finalidade aumentar o respeito e qualidade da atenção a mulher } \\
\text { durante o parto. }\end{array}$ \\
\hline $\begin{array}{l}\text { Jardim, D. M. B., } \\
\text { Moderna, C. M. }\end{array}$ & $\begin{array}{l}\text { A violência obstétrica no cotidiano } \\
\text { assistencial e suas características }\end{array}$ & 2018 & $\begin{array}{l}\text { A violência obstétrica além de um problema de saúde pública também viola os } \\
\text { direitos humanos com seus atos negligentes, discriminatórios e desrespeitosos. Na } \\
\text { tentativa de findar essa realidade é necessária uma conscientização, melhora das } \\
\text { políticas públicas e leis que visam proteger as mulheres. }\end{array}$ \\
\hline $\begin{array}{l}\text { Lansky, S., Sousa, K. } \\
\text { V., Peixoto, E. R. de } \\
\text { M. }\end{array}$ & $\begin{array}{l}\text { Violência obstétrica: influência da } \\
\text { Exposição Sentidos do Nascer na } \\
\text { vivência da gestante }\end{array}$ & 2019 & $\begin{array}{l}\text { A violência obstétrica é responsável pela forma como a sociedade enxerga o parto. } \\
\text { Além disso o artigo trouxe uma iniciativa chamada Sentidos do Nascer que visa } \\
\text { aumentar o conhecimento das gestantes sobre a violência, consequentemente busca } \\
\text { reduzir o excesso de cesarianas e apoiar a disseminação de boas práticas na assistência } \\
\text { ao parto e nascimento. }\end{array}$ \\
\hline $\begin{array}{l}\text { Marques, G. M., } \\
\text { Nascimento, D. Z. }\end{array}$ & $\begin{array}{l}\text { Alternativas que contribuem para a } \\
\text { redução da violência obstétrica }\end{array}$ & 2019 & $\begin{array}{c}\text { Os projetos "Parto adequado", e "Apice On”, são algumas alternativas que foram } \\
\text { apresentadas no Brasil que busca qualificar os funcionários e seus serviços quanto ao } \\
\text { cuidado das gestantes no parto e puerpério. }\end{array}$ \\
\hline $\begin{array}{l}\text { Michelle, S., } \\
\text { Marcelino, M. C., } \\
\text { Rodrigues, L. S. P. }\end{array}$ & $\begin{array}{l}\text { Violência obstétrica na visão de } \\
\text { enfermeiras obstétricas }\end{array}$ & 2014 & $\begin{array}{l}\text { O relato de experiência traz suas vivências em relação a violência obstétrica. E exalta } \\
\text { a necessidade de mudanças. Quanto a isso o Ministério da Saúde junto ao Ministério } \\
\text { da Educação e Ciência vem auxiliando na formação de enfermeiros obstétricos, que } \\
\text { demostrou uma melhora na assistência da mulher, além de aliar esses profissionais a } \\
\text { rede cegonha. }\end{array}$ \\
\hline $\begin{array}{l}\text { Oliveira, T. R. De., } \\
\text { Costa, R. E. O. L., } \\
\text { Monte, N. L. }\end{array}$ & $\begin{array}{l}\text { Percepção das mulheres sobre } \\
\text { violência obstétrica }\end{array}$ & 2017 & $\begin{array}{l}\text { É necessário que os profissionais e sociedade busquem por atendimento adequado as } \\
\text { mulheres, para que estas tenham o respeito e assistência necessária e humanizada para } \\
\text { o momento do parto. O trabalho visa trazer a necessidade dessa conscientização para a } \\
\text { melhorar a realidade. }\end{array}$ \\
\hline $\begin{array}{l}\text { Oliveira, V. J., Penna, } \\
\text { C. M. de M. }\end{array}$ & $\begin{array}{l}\text { O discurso da violência obstétrica } \\
\text { na voz das mulheres e dos } \\
\text { profissionais de saúde }\end{array}$ & 2017 & $\begin{array}{l}\text { O trabalho revela que a forma como a mulher é tratada pode interferir na escolha do } \\
\text { tipo de parto. Traz também a visão dos médicos que discordam sobre a realidade da } \\
\text { violência obstétrica apresentada pela mídia, e também a visão das mulheres que } \\
\text { contrapõem a dos profissionais. }\end{array}$ \\
\hline Palharini, L.A. & $\begin{array}{l}\text { Autonomia para quem? O discurso } \\
\text { médico hegemônico sobre a } \\
\text { violência obstétrica no Brasil }\end{array}$ & 2017 & $\begin{array}{c}\text { Este artigo busca ampliar o acesso a informação para que a mulher enfim possa } \\
\text { assumir o papel de protagonista do parto. Visa que esse tema deve ser abordado desde } \\
\text { a escola, nos museus, em vários locais públicos e situação que vão além da esfera } \\
\text { biomédica, para que deixe de ser um assunto tabu. }\end{array}$ \\
\hline $\begin{array}{l}\text { Pereira, J. S., Jordana, } \\
\text { S., Borges, N.A. }\end{array}$ & $\begin{array}{l}\text { Violência obstétrica: ofensa à } \\
\text { dignidade humana }\end{array}$ & 2016 & $\begin{array}{l}\text { Os profissionais da saúde cometem diversos erros, desde da forma de falar até suas } \\
\text { ações, que ofendem, discriminam, e desrespeitam a mulher. Na tentativa de diminuir } \\
\text { essa realidade algumas políticas públicas foram criadas e buscam o atendimento } \\
\text { integral e de qualidade das gestantes. Além de orientá-las quanto seus direitos, e } \\
\text { incentivam a denúncia quando estes não forem cumpridos. }\end{array}$ \\
\hline $\begin{array}{l}\text { Rosa, R. B., } \\
\text { Schraiber, A. F., } \\
\text { Blima, L. }\end{array}$ & $\begin{array}{l}\text { Violência: conceito e vivência } \\
\text { entre acadêmicos da área da saúde }\end{array}$ & 2010 & $\begin{array}{l}\text { A maioria dos acadêmicos da área da saúde como medicina, enfermagem e } \\
\text { odontologia já vivenciaram situações de violência, mas se sentem reféns por não } \\
\text { conseguirem denunciar seja pela hierarquia imposta, medo, ou por acharem que tudo } \\
\text { não passa de situações técnicas necessárias. Também afirma que apesar dos } \\
\text { acadêmicos se sentirem imóveis querem que o paciente reage de alguma forma. A } \\
\text { discussão sobre o tema nas universidades e meios acadêmicos é de suma importância } \\
\text { para prepará-los para agir e saber lidar nessas situações. }\end{array}$ \\
\hline $\begin{array}{l}\text { Rodrigues, D. P., } \\
\text { Alvez, V. H., Vieira, } \\
\text { R. S. }\end{array}$ & $\begin{array}{l}\text { A violência obstétrica no contexto } \\
\text { do parto e nascimento }\end{array}$ & 2018 & $\begin{array}{l}\text { Práticas retrógradas como manobra de Kristeller, episiotomia, proibição dos } \\
\text { movimentos da mulher, independente da ação seja ela de cunho físico, psicológico, } \\
\text { sexual, ou institucional classifica-se como violência obstétrica. A raiz desse problema } \\
\text { está enraizado na educação dos médicos e na falta de estrutura dos hospitais que não } \\
\text { garantem um lugar seguro para as mulheres em trabalho de parto. }\end{array}$ \\
\hline Ministério da Saúde & Projeto maternidade segura & 2000 & $\begin{array}{l}\text { O projeto tem o objetivo de melhorar a qualidade do atendimento materno-infantil, } \\
\text { buscando aperfeiçoar o atendimento integral. Além disso o projeto maternidade } \\
\text { segura junto ao Ministério da Saúde complementaram portarias para garantir uma } \\
\text { gestação, parto e pós-parto seguros. }\end{array}$ \\
\hline
\end{tabular}




\begin{tabular}{|c|c|c|c|}
\hline $\begin{array}{l}\text { Sena, L. M., Tesser, } \\
\text { C. D. }\end{array}$ & $\begin{array}{l}\text { Violência obstétrica no Brasil e o } \\
\text { ciberativismo de mulheres mães: } \\
\text { relato de duas experiências }\end{array}$ & 2017 & $\begin{array}{l}\text { Os relatos de experiência contribuem para gerar engajamento, reflexões e debates } \\
\text { sobre a temática da violência obstétrica. Assim a internet auxilia nas estratégias de } \\
\text { promoções da saúde da mulher, empoderamento feminino, e um maior apoio político. }\end{array}$ \\
\hline $\begin{array}{l}\text { Tesser, C. D., } \\
\text { Knobel, R., } \\
\text { Andrezzo, Halana F. } \\
\text { de A., Diniz, S. G. }\end{array}$ & $\begin{array}{l}\text { Violência obstétrica e prevenção } \\
\text { quaternária: o que é e o que fazer }\end{array}$ & 2015 & $\begin{array}{l}\text { A prevenção quaternária precisa da participação dos profissionais. Além da atuação } \\
\text { clinica que reforça o cuidado com a gestante, como também suporte e participação } \\
\text { social dos movimentos das mulheres, para que as reivindicações sejam atendidas. }\end{array}$ \\
\hline $\begin{array}{c}\text { Vieira, T. F. S., } \\
\text { Lima,M. A. C., } \\
\text { Costa, A. T., } \\
\text { Teixeira, L. A. M., } \\
\text { Muniz, BM.B. }\end{array}$ & $\begin{array}{l}\text { Conhecimento das mulheres sobre } \\
\text { violência obstétrica: uma revisão } \\
\text { sistemática }\end{array}$ & 2020 & $\begin{array}{c}\text { É notório que as mulheres não tem conhecimento sobre a violência obstétrica o que } \\
\text { influencia na persistência dessa pratica e não reconhecimento das mesmas pelas } \\
\text { vítimas. }\end{array}$ \\
\hline $\begin{array}{l}\text { Zaami, S., Stark, M., } \\
\text { Beck, R., Malvasi, } \\
\text { A., Marinelli, E. }\end{array}$ & $\begin{array}{l}\text { A episiotomia sempre equivale à a } \\
\quad \text { violência em obstetrícia? } \\
\text { Episiotomia rotineira e seletiva na } \\
\text { prática obstétrica e questões legais }\end{array}$ & 2019 & $\begin{array}{l}\text { A episiotomia é vista como uma forma de violência obstétrica e uma mutilação } \\
\text { quando desnecessária. A falta de padrão quanto a realização da episiotomia faz com } \\
\text { que se torne difícil o controle da mesma. }\end{array}$ \\
\hline
\end{tabular}

Fonte: Autores.

Os artigos analisados levaram a constatação que praticas consideradas deletérias e/ou desnecessárias estão constantemente presentes na vivencia obstétrica. Essas podem ser de cunho físico, psicológico, sexual, ou institucional e classificam-se como violência obstétrica. Destacar que a visão desses atos como não violentos por muitos durante a gestação, parto e pós-parto evidencia a necessidade de mais estudos e investigações em relação ao conhecimento da gestante a respeito dessas intervenções. Reconhecer que determinadas ações praticadas durante o parto versam como violência obstétrica é o pilar para diminuição do contingente de mulheres que sofrem com esse tipo de atitude medica, fazendo com que essas assumam o papel de protagonista no parto.

\section{Conclusão}

Após a síntese dos achados de todos os artigos analisados, compreendeu-se a identificação das características da violência obstétrica como um evento evidente expresso como negligência por parte dos profissionais de saúde, ou qualquer pessoa que prejudique de alguma forma o pré e pós parto, por meios de imprudência, omissão, atos discriminatórios e desrespeitosos, que são legitimados pelas relações que possivelmente simbolizaram o poder e saber técnico científico, e que de qualquer modo naturalizou ou banalizou sua ocorrência no cenário obstétrico.

Assim, entendendo-se as formas de violência obstétrica existentes e onde ocorrem, a importância de debater esse assunto para alcançar melhorias tanto na qualidade do atendimento quanto na formação acadêmica, para que assim ocorra uma diminuição significativa na prática da violência obstétrica.

Portanto, fica evidente que é de suma importância os estudos futuros acerca das práticas de violência obstétrica, visando, não de forma única, mas imprescindível, o médico ser visto como um elemento chave no processo de remodelação na assistência à parturiente e ao bebê. Sendo que este é membro indissociável da equipe de saúde tendo potencial para sensibilização destes quanto a prevenção e promoção de boas práticas, além de possuir virtude para empoderar as mulheres durante todo o trajeto a ser percorrido para o nascimento de seu filho, contribuindo, desse modo, para uma assistência qualificada e humanizada.

\section{Referências}

Andrade B. P., Padilha, B., \& Aggio, C. M. (2014) Violência obstétrica: a dor que cala. Anais do III Simpósio Gênero e Políticas públicas. Londrina, PR, Brasil. <http://www.uel.br/eventos/gpp/pages/arquivos/GT3_Briena\%20Padilha\%20Andrade.pdf〉.

Barboza, L. P., \& Mota, A. (2016). Vivências de sofrimento entre gestantes no Brasil. Revista Psicologia, Diversidade e Saúde, Violência obstétrica., 5(1). 1. $<$ https://www5.bahiana.edu.br/index.php/psicologia/article/view/847>.

Botelho, L. L. R. Cunha, C. C. de A., \& Macedo, M. (2011) O método da revisão integrativa nos estudos organizacionais. Gestão E Sociedade, Belo Horizonte-MG.121-136. https://doi.org/10.21171/ges.v5i11.1220 
Broome, M. E. (2006). Integrative literature reviews for the development of concepts. In: A. A. Revisão sistemática e meta-análise. <www.metodologia.org/meta1.PDF>.

Carvalho, I. Da S., \& De Brito, R. S. (2017). Formas de violência obstétrica vivenciadas por puérperas que tiveram parto normal. Enfermería Global, $16(3): 71$.

Diniz, S. G., Salgado, H. D. O., Aguiar A., \& Halana, D., F. (2015). Abuse and disrespect in childbirth care as a public health issue in Brazil: Origins, definitions, impacts on maternal health, ad proposals for its prevention. Journal of Human Growth and Development, $25(3): 377$.

Humanos CdD. (2005). <http://www.dhnet.org.br/dados/cartilhas/a_pdf/901_cartilha_cdh_sp_genero.pdf.>

Jardim, D. M. B., \& Moderna, C. M. (2018). Obstetric violence in the daily routine of care and its characteristics. Revista Latino-Americana de Enfermagem, 26(s/n). <https://pubmed.ncbi.nlm.nih.gov/30517571/>.

Lansky, S., Sousa, K. V., \& Peixoto, E. R. de M. (2019). Violência obstétrica: influência da Exposição Sentidos do Nascer na vivência das gestantes. Ciência \& Saúde Coletiva, 24(8): 2811. <https://pubmed.ncbi.nlm.nih.gov/31389530/>.

Marques, G. M., \& Nascimento, D. Z. (2019). Alternativas que contribuem para a redução da violência obstétrica. Ciência \& Saúde Coletiva, 24(12):47434744. <https://pubmed.ncbi.nlm.nih.gov/31778523/>.

Michelle, S., Marcelino, M. C., \& Rodrigues, L. S. P. (2014). Violência obstétrica na visão de enfermeiras obstetras. Rev. Rene, 15(4):720-728. $<$ http://repositorio.ufc.br/handle/riufc/11479>.

Oliveira, T. R. De., Costa, R. E. O. L., Monte, N. L., et al. (2017). Percepção das mulheres sobre violência obstétrica. Rev. enferm. UFPE. 40 -46. $<$ https://pesquisa.bvsalud.org/portal/resource/fr/bde-30270>.

Oliveira, V. J., \& Penna, C. M. de M. (2017). Discussing obstetric violence through the voices of women and health professionals. Texto \& Contexto Enfermagem, 26(2). <https://www.scielo.br/scielo.php?pid=S0104-07072017000200331\&script=sci_arttext\&tlng=pt>.

Palharini, L. A. (2017). Autonomia para quem? O discurso médico hegemônico sobre a violência obstétrica no Brasil. Cadernos Pagu. (49). <https://www.scielo.br/scielo.php?pid=S0104-83332017000100307\&script=sci_arttext >.

Pereira, J. S., Jordana, S. \& Borges, N. A. (2016). Violência obstétrica: ofensa a dignidade humana. Brazilian Journal of Surgery and Clinical Research. 15(s/n):103-108. <https://www.repositorio.ufop.br/handle/123456789/6646>.

Rosa, R. B., Schraiber, A. F., \& Blima, L., et al. (2010). Violência: conceito e vivência entre acadêmicos da área da saúde. Interface - Comunicação, Saúde, Educação, 14(32):81-90. <https://www.scielo.br/pdf/icse/v14n32/07.pdf>.

Rodrigues, D. P., Alvez, V. H., \& Vieira, R. S. (2018). A violência obstétrica no contexto do parto e nascimento. Rev. enferm. UFPE. $236-246$.

Rosa, R. et al. (2010). Violence: concept and experience among health sciences undergraduate students. Interface - Comunic., Saude, Educ., 14(32):81-90.

Saúde Md. (2020). <http://bvsms.saude.gov.br/bvs/folder/10006002455.pdf>

Sena, L. M., \& Tesser, C. D. (2016). Violência obstétrica no Brasil e o ciberativismo de mulheres mães: relato de duas experiências. Interface - Comunicação, Saúde, Educação, 21(60):209-220. <https://www.scielosp.org/article/icse/2017.v21n60/209-220>.

Sousa, L. M. M. S., Marques-Vieira, C. M. A., Severino, S. S., \& Antunes, A. V. (2017). Metodologia de revisão integrativa da literatura em enfermagem.

Tesser, C. D., Knobel, R., Andrezzo, Halana F. de A., \& Diniz, S. G. (2015). Violência obstétrica e prevenção quaternária: o que é e o que fazer. Revista Brasileira Medicina Família Comunidade, 10(35):1-12. doi:10.5712/rbmfc10(35)1013

Vieira, T. F. S., Lima, M. A. C., Costa, A. T., Teixeira, L. A. M., \& Muniz, BM.B. (2020). Conhecimento das mulheres sobre violência obstétrica: Uma revisão sistemática. Braz. J. Hea. Rev., 3(4):9912-9925

Zaami, S., Stark, M., Beck, R., Malvasi, A., \& Marinelli, E. (2019). Does episiotomy always equate violence in obstetrics? Routine and selective episiotomy in obstetric practice and legal questions. European review for medical and pharmacological sciences, 23(5). 